\title{
Social relationships and patterns of use in urban public spaces in China and the United Kingdom
}

Jingwen $\mathrm{CAO}^{\mathrm{a}}$ and Jian $\mathrm{KANG}^{\mathrm{a}, \mathrm{b}}$

aSchool of Architecture, University of Sheffield, Western Bank, Sheffield S10 2TN, United Kingdom, Jcao9@sheffield.ac.uk

${ }^{b}$ Institute for Environmental Design and Engineering, The Bartlett, University College London, London WC1H 0NN, United Kingdom, J.kang@ucl.ac.uk

*Corresponding Author: J.kang@ucl.ac.uk, UCL Institute for Environmental Design and Engineering, The Bartlett, University College London (UCL), London WC1H 0NN, United Kingdom. Tel: +44 (0) 2031087338

\begin{abstract}
Public spaces are social places that enhance social life and foster social interactions.

However, there is a lack of analysis of the patterns of use by people in various types of social relationships. Observational data on four public spaces in Suzhou, China, and Sheffield, UK, assessed users' personal characteristics, activities and spatial occupancies in public spaces. Site factors were not related to personal characteristics, but age and group size were culturally different. Activities and spatial occupancies differed between unaccompanied and accompanied users. Compared to single users, users in groups tended to participate in multiple activities at once, and their activities included more interactions. Single users' spatial distributions conformed to the edge effect, but users in groups were evenly distributed in the spaces. Three types of social relationships were defined: Intimate Pair, Intimate Group and Social Group. Intimate Pairs were most likely to use mobile phones and use private spaces, Intimate Groups were most likely to be talking and sitting and to use park amenities, and Social Groups were most likely to be playing games and relaxing in spacious open areas. Regarding spatial occupancy, Intimate Pairs and Social Groups were most likely to use the middle and peripheral regions, and the Intimate Groups tended to be evenly distributed in the spaces. The results of this study stress the importance of designing public spaces for the types
\end{abstract}


of users expected to use the spaces and to consider various types of social relationship groups.

Keywords: Public space, usage pattern, observation method, social relationships, edge effect

\section{Introduction}

Public spaces are social places where people can linger and interact, and they are intended to be open and accessible to all people. Previous studies on public spaces have focused on environmental comfort, such as acoustic comfort (Yang \& Kang, 2005) or sensation comfort (Xiao et al., 2018). The comfort level is believed to enhance or diminish the sociability of public spaces. The sociability aspect has been emphasized because a lively and active public spaces are believed to foster and enhance users' social relationships and further build place attachment (Project for Public Spaces, 2017; Gehl \& Svarre, 2013; Thwaites\& Simkins, 2005). Social relationships and interactions are drawing attention because they benefit individual wellbeing and because isolation increases feelings of depression and stress (Balducci \& Checchi, 2009).

Based on the notion of relationship intensity, Hall (1992) suggested that types of social relationships observed in public spaces could be identified by the physical distances between individuals. In other words, people are closer together as their relationship intensity increases. He categorized four levels of relationship intensity based on physical distance: (1) intimate distance, (2) personal distance, (3) social distance, and (4) public distance. Gehl (1987) analysed the social relationships of public space users using Hall's distance formula to categorize five types of contact: (1) none, (2) passive, (3) chance, (4) familiar stranger, and (5) friend.

Gehl (1987) mostly focused on the process of building new social ties that transition contacts from stranger to acquaintance status. However, people usually arrive at public spaces with companions, such as lovers, family members, or friends, and they already are socially interacting. Staats and Hartig (2004) pointed out that companion status might influence the quality of individuals' experiences in public spaces. They suggested that being accompanied increases preference for the urban instead of the natural environment. However, we lack systematic analysis of the ways that people feel and behave in public spaces when 
accompanied by various types of companions. Thus, this study analysed people involved in various social relationships relative to their patterns of use of public spaces.

A pattern of use refers to the ways that people use a space, which usually comprises activity and spatial occupancy (Goličnik \& Thompson, 2010). Activities in the public space are varied and are described as 'ballet' by Jacobs (1961), indicating that individual dancers have distinctive parts. Activities in public spaces usually are identified from users' behaviours, such as walking, sitting, standing and so on (Marcus \& Francis, 1998). Sometimes, people simultaneously engage in two or three types of activities, such as sitting while eating. Gehl (1987) identified three types of activity in public spaces related to environmental conditions: necessary, optional and social. Necessary activities occur regardless of the environmental quality of the space, whereas optional and social activities occur under certain environmental conditions.

Regarding spatial occupancy in public spaces, Whyte (1980) pointed out that people tend to prefer occupying the peripheries over central areas of public squares, which De Jonge (1967-68, p. 10-11) presented as the 'edge effect'. Gehl (1987) acknowledged this phenomenon and added that some public space characteristics might offer edge experiences, such as columns or trees. Observation is the fundamental method used to study public spaces (Bechtel et al., 1987) because it is a simple and efficient way to learn about their uses (Cooper \& Francis, 1998), and it is a useful way to collect data on patterns of use. The relationship between uses and spatial occupancies are found through behavioural mapping, which historically has been used in environmental behaviour studies (Ittelson, 1970; Lipovská \& Štěpánková, 2013).

People's uses of public spaces vary by their social and demographic characteristics (Yu \& Kang, 2008; Whyte, 1980). Gender and age are the most common of those characteristics; for example, women, but not men, tend to be sensitive to environmental conditions and avoid being seen. Thus, women tend to seek backyard experiences that offer comfort, relief, a sense of safety and relaxation, whereas men tend to seek front yard experiences to access the publicness, social interaction, and involvement offered by a space (Gehl, 1987; Marcus \& Francis, 1998; Whyte, 1980). Regarding age differences, older people tend to be relatively sensitive to the presence of others and to avoid evening or night 
experiences. Younger adults tend to visit public spaces in large groups and to occupy large areas (Holland et al., 2007). However, the previous studies did not compare users in light of their social relationships.

Following Hall (1992), this study analysed patterns of use in public spaces based on social relationship types (intensity) by observing people at four public spaces in China and the UK. Using data on the sites and cultural factors, social relationship types were identified, compared, and analysed in terms of activities and spatial occupancy. Those results were used to categorize the patterns of use of the public spaces by social relationship type.

\section{Material and methods}

\section{Observation Process}

Since the 1960s, the observation method has been used widely by researchers in architecture and landscaping public space studies (Lipovská \& Štěpánková, 2013). Researchers use the observation method to assess and map activity in the setting of plazas, parks, and many other kinds of public spaces (Francis, 1984). Among those practices, William Whyte's (1980) observation of the use of plazas is a widely recognized approach for analysing the relations between people and public spaces. Gehl (1987) and the Project for Public Spaces (1981) applied similar methods to commercial streets and neighbourhood public spaces. The method is relatively cost-effective and time-effective, and it consistently yields useful data on actual uses of designed places (Cooper \& Francis, 1998). According to Ittelson (1970), the process of observation has five steps:

1. A graphic rendering of the area(s) observed

2. A clear definition of the human behaviours observed, counted, described or diagrammed

3. A schedule of repeated times during which the observations and recordings occur

4. A systematic procedure of observing

5. A coding and counting system that minimizes the effort needed to record observations 
Along with the process recommended by Ittelson (1970), Gehl \&Svarre (2013) advised observing the space through note taking, documenting, photographing, and videotaping.

Two studies (Gehl \& Svarre, 2013; Goličnik Marusic \& Marusic, 2012) targeted analysing patterns of use in public spaces (Table 1). Both studies found that patterns of use strongly related to the time of day, weather, and season. Thus, this study's observations were designed to cover various times of day, various weather conditions, and at least two seasons. A pilot study identified an observation span that was appropriate for observing and recording. Observations were photographed and videotaped to verify the recorded visual observations.

\begin{tabular}{|c|c|c|}
\hline Aspect & Gehl and Svarre (2013) & Goličnik Marusic and Marusic (2012) \\
\hline $\begin{array}{l}\text { Study } \\
\text { objectiv } \\
\text { e }\end{array}$ & $\begin{array}{l}\text { Assess gender, age, activity } \\
\text { and social relationship } \\
\text { differences }\end{array}$ & $\begin{array}{l}\text { Assess gender, age, activity, duration and spatial } \\
\text { occupancy differences }\end{array}$ \\
\hline Site & $\begin{array}{l}\text { Various public spaces in } \\
\text { Europe }\end{array}$ & Urban squares and parks in Europe \\
\hline $\begin{array}{l}\text { Observ } \\
\text { ational } \\
\text { span }\end{array}$ & $\begin{array}{l}\text { - } 15 \text { minutes each hour from } \\
10 \text { AM to } 10 \text { PM } \\
\text { - Every day } \\
\text { - Defined by weather } \\
\text { - Two seasons }\end{array}$ & $\begin{array}{l}\text { - } 10 \text { to } 40 \text { minutes each: } \\
\text { - Morning (10 AM to noon) } \\
\text { - Early afternoon (12:01 PM to } 4 \text { PM) } \\
\text { - Afternoon (4:01 PM to 6 PM) } \\
\text { - Early evening/evening (6:01 PM to 9 PM) } \\
\text { - Defined by weather } \\
\text { - One season }\end{array}$ \\
\hline $\begin{array}{l}\text { Observ } \\
\text { ational } \\
\text { position }\end{array}$ & One position & $\begin{array}{l}\text { One location (sub-areas used depending on the size of } \\
\text { space) }\end{array}$ \\
\hline Activity & $\begin{array}{l}\text { Counting, mapping, tracing, } \\
\text { tracking, photographing, } \\
\text { taking notes and test walks }\end{array}$ & Behavioural mapping, tracking and GIS recording \\
\hline
\end{tabular}

Table 1. Comparison of methodologies

Behavioural mapping was used to record users' activities and spatial occupancies. Behavioural maps can include all of a site's information on one map and link users' behaviours to their spatial settings. To create a behavioural map, an accurate scale of the site, clearly defined types of activities and details about behaviours to be observed should be pre- 
determined (Goličnik Marusic \& Marusic, 2012). To create an accurate site map for this study, accurate locations of spatial characteristics, such as benches and trees, were needed to determine the users' spatial occupancies. Labelling activity types depends on the observers' opinions, which are more or less subjective (Zeisel, 1984). To avoid variations across observers recording user activities, this study defined activities to include every specific human action, such as users simultaneously engaged in two activities or users stopping one activity and starting another. All of these activities should be recorded during the observation time. For optimal efficiency, users' activities were directly recorded onto the behavioural map using symbols accurately drawn on the map at the locations of the activities.

This study identified types of social relationship by distance following Gehl's (1987) application of Hall's (1992) social distance theory. Hall (1992) suggested four types based on distance: (1) intimate (zero to $45 \mathrm{~cm}$ ), observed as expressions of tenderness, comfort, love or strong anger; (2) personal ( $46 \mathrm{~cm}$ to $1.30 \mathrm{~m}$ ), observed as conversations between close friends or family; (3) social (1.31 m to $3.75 \mathrm{~m})$, observed as ordinary conversations with friends, acquaintances and so on; and (4) public ( $>3.75 \mathrm{~m})$, observed as informal situations. Gehl (1987) employed two relationship intensities: (1) intense emotional contact was at a distance of zero to $.5 \mathrm{~m}$ and (2) less intense emotional contact was at a distance of .51 to 7.0 m. Hall's (1992) categories were more elaborate than Gehl's (1987), and he elucidated the relationship types, pointing out that the type could be determined by sight, sound, touch and smell. For example, the intimate level/distance might involve the individuals' physical contact (pelvis, thigh, or head; Hall, 1992, p. 117). The use of a distance measure widens the observational sphere of social relations. Therefore, this study identified the intensity of social relationships according to Hall's distance measurements. A further category was formed based on the intensity level.

\section{Site selection}

Four cities' public squares were selected as the study sites because they experienced a variety of users in numerous types of social relationships daily. The city public square is a type of the grand public place in Marcus and Francis' (1998) five-category typology of urban public spaces: street plaza, corporate foyer, urban oasis, transit foyer, and grand public place. 
The city public square is defined in this study as a centrally located and often historical place where major thoroughfares intersect. In this study, two of the public squares were in Sheffield, UK, and two of them were in Suzhou, China.

The study sites were popular places, and they all had geographical advantages and symbolic histories. Table 2 summarises the sites' characteristics. Peace Garden had a large grass lawn and dramatic fountain. Barkers Pool was located between City Hall and John Lewis (a shopping mall), and it served as a pathway in the central city. It served more pedestrians commuting to the work than Peace Garden. Central Park Square (Suzhou), built to commemorate the industrial park symbolizing cooperation between China and Singapore, faced Xingming Street, which is one of the city's main streets. Although it occupied a massive space, it had little green area and no seating. Guanqian Square was the smallest of the four sites, and it was inside Guanqian's commercial zone, which is a famous business area for residents and visitors. It had a large area of trees, several flowerbeds, and many benches for users to sit and rest. A broken fountain was in the centre of the square for many years.

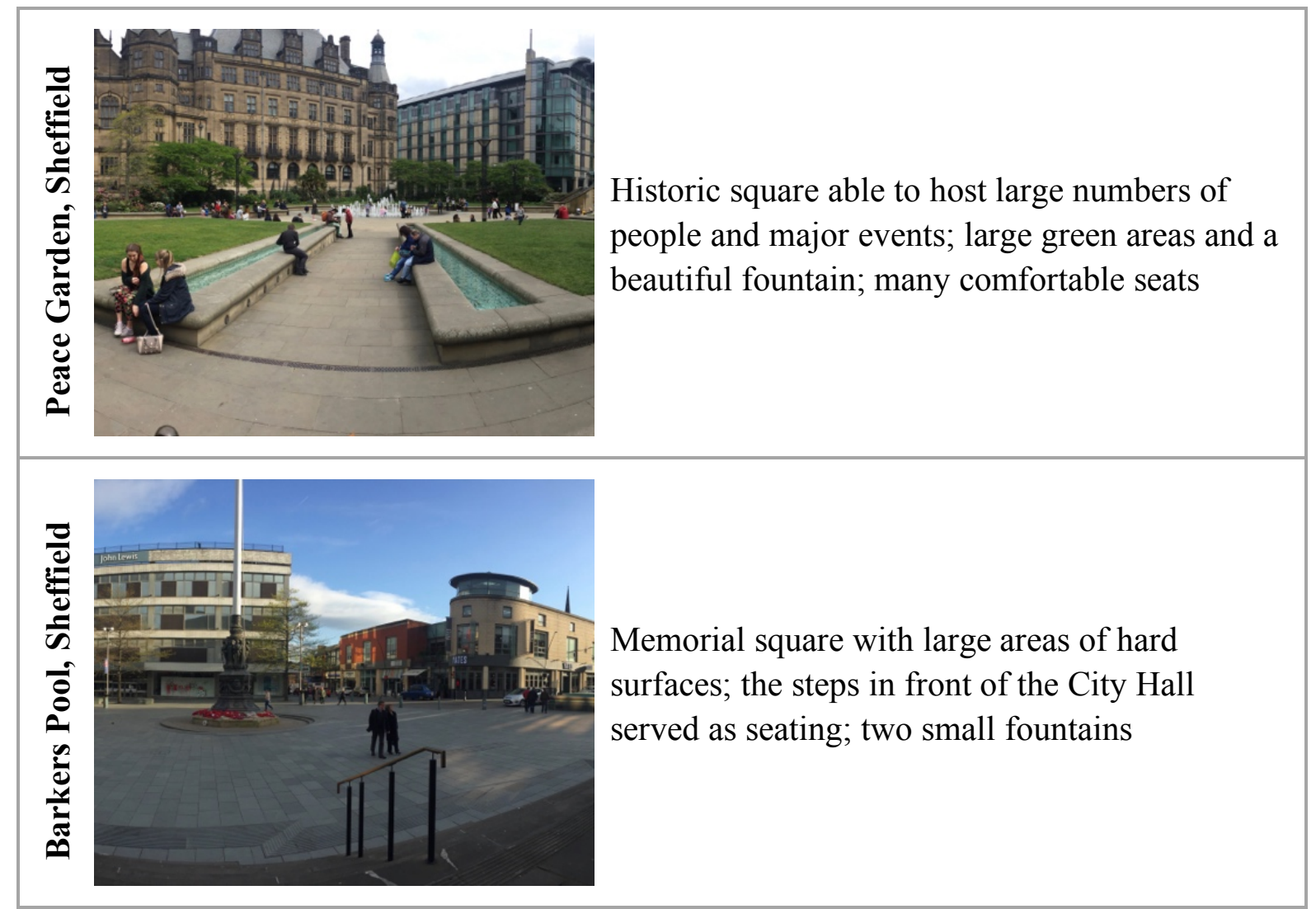




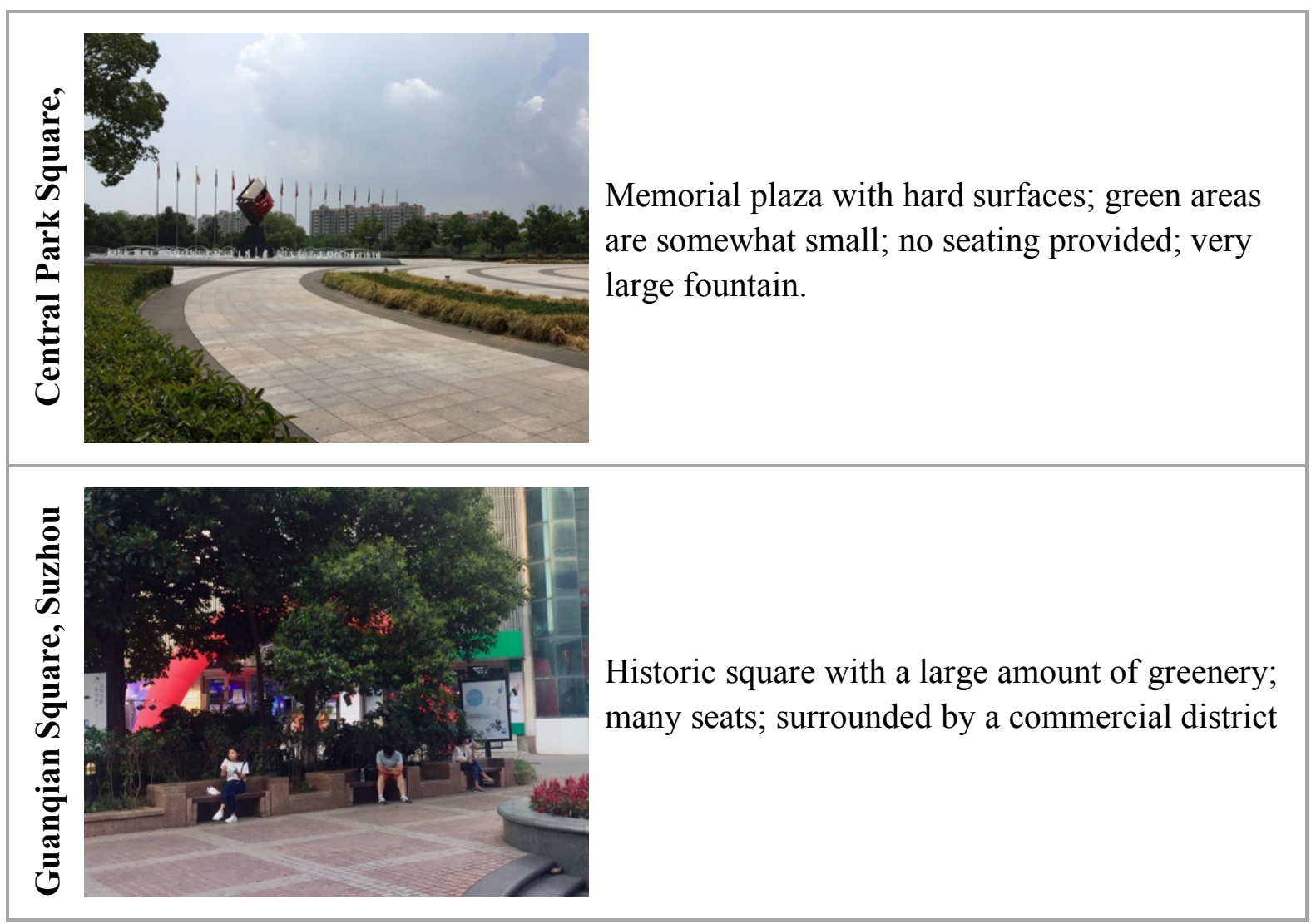

Table 2. Descriptions of the study sites

\section{Data collection}

The data were collected in April to May 2017 (Sheffield) and July to August 2017 (China). Observations were conducted throughout the week and under various weather conditions (sunny, windy, cloudy, and so on). Observations occurred four times of day (9 AM to noon), (12:01 PM to $2 \mathrm{PM}),(2: 01 \mathrm{PM}$ to $5 \mathrm{PM})$ and (6 PM to $10 \mathrm{PM})$. Ten observations lasting 20 to 40 minutes each were made at each study site. Most of the observations occurred during weather that was mild enough to attract people to the public space. Accurate site maps were prepared before the observations were made. The maps used the symbols ' $\mathrm{X}$ ' and ' $\mathrm{O}$ ' to represent men and women, respectively, and open circles were used to indicate groups. The locations of the groups and individuals were recorded on the site maps. Group members were assigned identification numbers, and data on age and activities were linked to the identification numbers. Some commonly observed activities are drawn using symbols combined with the gender symbols to increase efficiency. Age groups were categorized as children (younger than about 12 years), youths (about 13 to 25 years old), 
adults (about 26 to 50 years old) and elders (about 50 years or older). Short-term activities in the space, such as walking through it without stopping, were not included because the study's focus was on people who interacted in the spaces long enough to experience the environment.

The social relationship types were determined using Hall's (1992) distances. Whereas Hall (1992) covered relationships ranging from intimates to strangers, this study assumed that all the users were at least acquainted with the people they interacted with and stranger interactions were dropped from the analysis. The observations were categorized into Hall's (1992) first three groups: (1) intimate (zero to $45 \mathrm{~cm}$ ), observed as expressions of tenderness, comfort, love or strong anger; (2) personal (46 $\mathrm{cm}$ to $1.30 \mathrm{~m}$ ), observed as conversations between close friends or family; and (3) social (1.31 m to $3.75 \mathrm{~m})$, observed as ordinary conversations with friends, acquaintances and so on. The distance measurement was intended to apply to the distance between two people, but groups comprised more than two individuals. Therefore, the distances of groups of three or more people were determined by computing the average distance within the groups. All distances were visually approximated.

Although more than one person usually performs the observations (e.g., Gehl\& Svarre, 2013; Whyte, 1980) with researchers using the same observational methods, this study's observations were made by one researcher. One reason for this was that, unlike studies that aim to understand an entire public space, the observations were simple and focused. Second, this study did not require a significant amount of subjectivity. Identifying gender, activities and distances were recorded as facts, and age was assessed in predetermined ranges based on common sense.

\section{Data analysis}

The analysis included 801 observations of 1,664 users. 367 alone users were observed, with 145 in Suzhou and 222 in Sheffield. 439 observations were conducted on accompanied users which account for 1297 users, with 485 in Suzhou, 812 in Sheffield. 24 memos of additional information were recorded on the notebook, which was helpful for city comparison. Age, gender and group size were quantitative values, and activities were recorded as descriptive terms, such as sitting, eating, or talking. Spatial occupancy was recorded on the maps using the symbols described above. Data on every observation were 
first manually mapped on observation sheets and then input into Microsoft Excel, Matlab, or Photoshop for further analysis, as follows.

1. Frequency analyses were performed on users' personal characteristics to summarize and compare by gender, age, and group size (Excel).

2. Activities were categorized by the clustering method (Matlab).

3. Spatial occupancy data were transformed into a digital map to analyse variation (Photoshop).

Group activities recorded through observations were complex because group members tended to simultaneously be engaged in several activities, such as standing, talking, and using a mobile phone, or sitting, eating, and talking. Therefore, the clustering method was used to identify patterns of group activities. The first step was manual semantic categorizing to improve the precision of the clusters. Then, 23 different activities were identified: sitting, talking, playing, standing, eating, drinking, contacting others using a phone, laying, smoking, playing with a phone, picnicking, touching others, drawing, looking around, kissing, hugging, photographing with a mobile phone, waiting, listening to music, reading, dancing and exercising. In the second step, some of these activities were merged together to simplify the data, such as combining photographing with a mobile phone, playing with a phone and contacting others with a phone into one activity named 'using a mobile phone'. Ten activities remained, as shown in Table 3.

\begin{tabular}{lcc}
\hline Activity category & Category content items & Frequency \\
\hline Sitting & & 324 \\
Standing & & 111 \\
Laying & Photographing with mobile phone & 13 \\
& Playing with phone & 31 \\
Using a mobile phone & Contacting others with phone & 44 \\
& Reading & 2 \\
Relaxing & Drawing & 2 \\
& Smoking & 14 \\
\hline
\end{tabular}




\begin{tabular}{lcc}
\hline & Looking around & 7 \\
& Listening to music & 2 \\
Talking & Eating and drinking & 91 \\
& & 310 \\
Physical intimacy & Kissing & 4 \\
& Touching others & 5 \\
Playing & Hugging & 4 \\
Waiting & & 92 \\
Exercising & & 19 \\
\end{tabular}

Table 3. Simplified activity types

In the third step, the clustering method categorized activity patterns using Matlab. The clustering was intended to reveal patterns of activity clusters based on K-means. In the Matlab program, cases were sorted into 3, 4, or 5 clusters based on their similarities. The clearest clustering was of five cluster types. Table 4 shows the cluster types, the numbers of cases in each of them, and their primary features. The clusters were defined by their features; for example, Cluster 1 is featured by the activity of 'relaxing', most sets of which were 'sitting/standing and relaxing'.

\begin{tabular}{ccl}
\hline Cluster type & Number of cases & \multicolumn{1}{c}{ Main features } \\
\hline $\mathbf{1}$ & 114 & Relaxing \\
$\mathbf{2}$ & 208 & Talking, sitting \\
$\mathbf{3}$ & 14 & Playing \\
$\mathbf{4}$ & 52 & Using a mobile phone \\
$\mathbf{5}$ & 51 & Standing \\
Total & 439 & \\
\hline
\end{tabular}

Table 4. The five cluster types 
Spatial occupancy was analysed by estimating the distance between a user and the centre of the public space. This determined where the users were placing themselves in the space and defined those placements according to the edge effect. To evaluate the edge effect, each map was divided into three regions from the centre to the periphery. The numbers of users in the three regions were counted, and those quantities were used to create line graphs to analyse the numbers of users from the centre to the fringe of each map.

\section{Results}

\section{Effects of the sites and cultural factors}

Chi-squared for contingency was used to analyse the site effects by comparing the users by gender, age and group size. Then, the differences among the four study sites were compared for consistency in these factors. The statistical value was compared to the critical value: $\mathrm{fx}=$ Chiinv (probability, the degree of freedom). Before performing the Chi-square test on group size, three unusually large groups were omitted $(50,58$, and 15 people) from the Central Park Square data. Extremely large groups used the public space for square dancing between 7 PM to 9:30 PM every day. The statistical values on age, size, and gender were $59.559,37.903$ and 1.146 , respectively, but only the age difference was statistically significant (59.559 > 26.217). The large statistics were at Central Park Square (40.430), which was a significantly different age composition about four times as large as the other three places. According to Figure 1, Central Park Square had a much larger share of elders $(24 \%)$ and a much smaller share of young adults $(2 \%)$ than the other public spaces. The high proportion of elders relates to their overrepresentation in the dance group. Although big dancing groups are tested and omitted from the data, some small dance groups made up of 3 or 4 older dancers remain. When the small dance groups were omitted from the data, the age compositions across the places were not significantly different. 


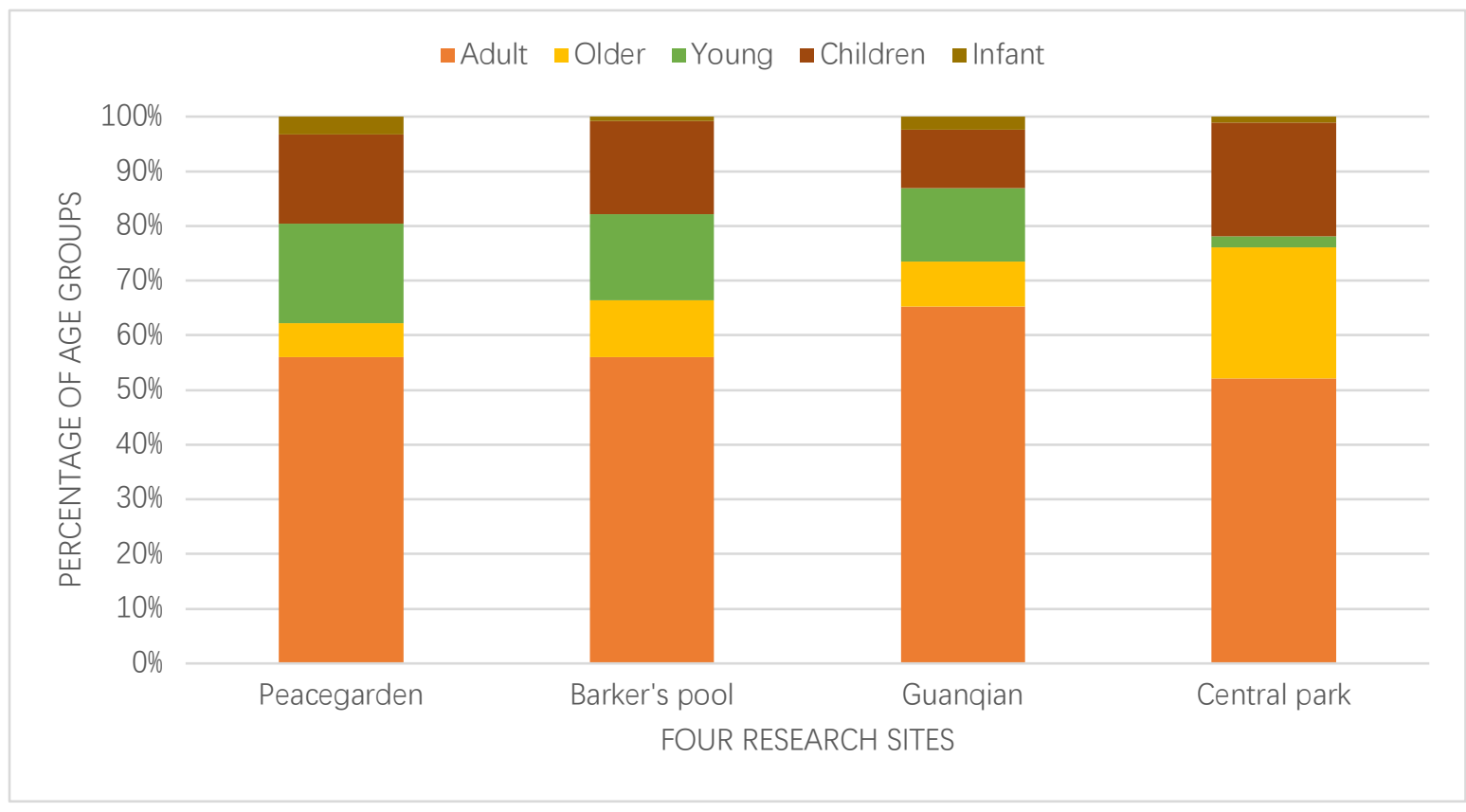

Figure 1. Age composition of the users observed at the study sites

The exceptional data at Central Park Square suggest cultural differences between China and the UK. Dance groups typically are observed in Chinese public spaces. Most of the dancers are middle-aged or older adults who seem well organized and consistent in their behaviours, and, during this study's observations, they even came to dance one day when it was lightly raining. Square dancing is a popular activity in China that is attracting millions of retired people. The participants are referred to as 'dancing grannies' by English news media (BBC News China, 2013), which suggests their age and gender. However, the dance group at Central Park Square was not only these 'grannies', and there seemed to be a balance of men and women participants. It may because different types of dancing are involved in. There are various types of dancing performing in Chinese squares, such as folk dancing, zombie dancing (Meng \& Kang, 2016). Unlike the random street performances observed at the Sheffield public squares, Chinese people regularly participated in those activities to enhance their health and enrich their lives. During the dancing, a large area of the space was occupied, and loud dance music was played, which seemed to negatively affect other users because they started to leave the place when the dancers came. To avoid noise, earphones have been gradually used to replace the speakers to deliver music (Zhou, 2014). Consequently, the 
dance group not only influenced the differences in age and group size, but it also influenced the normal uses of the space.

Cultural factors also influenced the amounts of time spent in the places and the activity types at Sheffield and Suzhou. According to the observation memo, users at the Suzhou places were more likely to use the public spaces at night. No users were observed in the Sheffield squares after dark (after 7:00 P.M. in April; after 8:00 p.m. in May.), whereas, in Suzhou, the numbers of users increased after 6:00 PM. Then, the Suzhou users gradually left from about 9:00 PM until about 11:30 PM. Except for the big amount of dancing people, many Suzhou users engaged in the evening activity of 'taking a walk after dinner'. Walking after dinner is considered a healthy exercise in China as evidenced by the maxim, "people who walk after dinner can live up to 99 years'. Peopled walked to the square to relax and then they returned home. The Sheffield users' activities were often observed as highly related to weather conditions because the number of users in the public spaces increased to nearly twice when the weather was pleasant. Users went there to rest on the grass and sunbathe or to picnic and enjoy the balmy weather. When the duration of sunshine becomes longer in summer, the street fairs are a common sight in these two squares. Great amount of people show up in the street fair to celebrate the summer. And those fairs are recognized as a common cultural currency and asset in the UK (Walker, 2015).

In sum, the sites were not obviously different regarding the personal characteristics of the users, but the cultural differences related to the Chinese dance group greatly influenced age and group size distributions in the public space where they occurred because the group was very large. When the dance group was not included in the statistical test, age, gender and group size were consistent across the study sites.

\section{Patterns of use between single and accompanied users}

One focus of this study was the differences and similarities between single and accompanied users regarding the characteristics of their patterns of use. The comparison found that the gender composition was different in the two groups and that accompanied users were relatively less likely to conform to the edge effect. Regarding gender, women were more likely than men to be in groups (accompanied), with 40\% versus 34\%. There were 
almost half as many unaccompanied women as there were men (9\% versus $17 \%)$. Valentine (1990) found that women avoided being alone in public because they were concerned about possible harassment, crime and violence, particularly at night. Some researchers who perceived public spaces as socially constructed have pointed out that men seemed to own and control public spaces, and urban geography historically has located men in public spaces and women in private spaces (Mowl \& Towner, 1995). The gender distribution regarding single versus accompanied users found in this study supports the notion that women are afraid to be alone in public spaces.

The activities of single and accompanied users were quite different from each other regarding type and composition. Unaccompanied users were mostly engaged in one or simultaneously in two activities, whereas group users tended to engage in more than two activities at the same time. The unaccompanied users participated in 13 types of activity: waiting, photographing, looking around, using a mobile phone, exercising, smoking, relaxing, standing, playing, sitting, eating, sleeping, or drinking. The most common activities were using a mobile phone (52.5\%) and waiting (13.3\%). Group users engaged in relatively more types of activity as described above in Table 3, and 23 different activities remained after the sorting process. The group activities included interactions with other group members, such as talking and playing. The most common group activities were sitting $(29.5 \%)$ and talking $(28.2 \%)$

The spatial occupancies of single users conformed to the edge effect, but that was not the case regarding accompanied users. Table 5 shows the spatial occupancy locations of single and accompanied users symbolized by black and red dots on the maps of the four study sites. Each site map shows the three regions from the centre to the periphery. The numbers of users in each region of each map were counted, and a line graph was created for each site (shown next to each map). The four line graphs show that the numbers of single users increased from the inner to the outer regions, and the numbers of accompanied users did not seem to have an edge effect pattern. Most of the accompanied users seemed to be in the middle regions. 


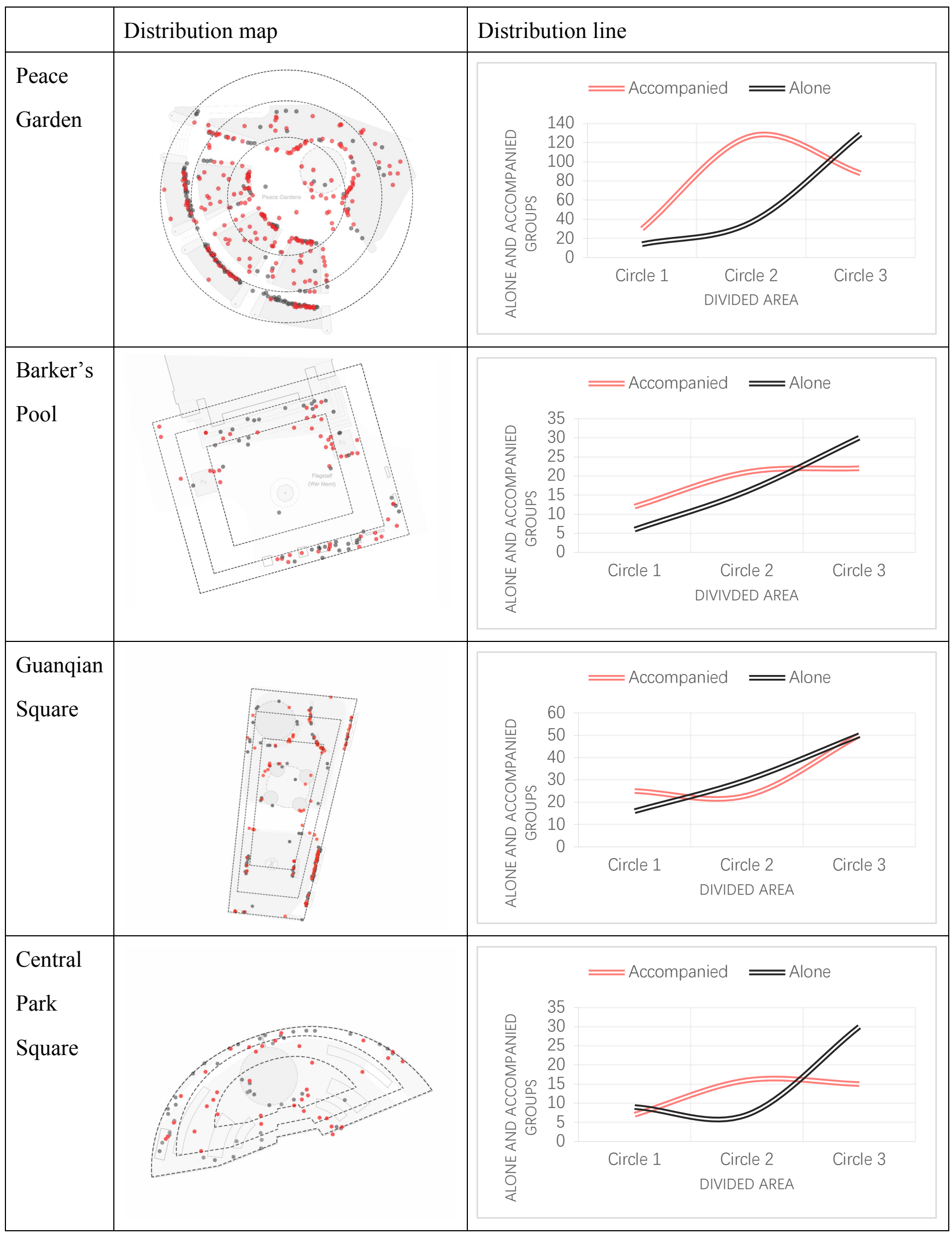

Table 5. Spatial occupancy of the users observed at the four public spaces

Legend: Red $=$ Accompanied users; black $=$ Alone users 
(Four line graphs show how alone and accompanied users distribute from the inner circle to the outer. Red line $=$ accompanied users; black line $=$ single users)

Source: Authors

The differences in the spatial occupancies between the single and accompanied users might be because single users tend to be more likely than accompanied users to engage in 'passive contact activities', meaning that they passively observe strangers (Gehl, 1987, p. 1213) and desire relatively more privacy and protection. De Jonge (1967-68) suggested that edge spaces offer a sense of security because individuals or groups might find it easier there to stay away from other people and they provide opportunities to survey the area. Stevens (2007) proposed that inexperienced or shy people are often found on the periphery to avoid uncertain or unsafe situations. Edge places offer protection because users can maintain a comfortable distance from strangers. Thus, single users might be similar to people, Stevens (2007) mentioned, who desire protection and privacy because they are alone. In this study, unlike group users, who mostly were involved in interactive activities, single users were engaged in passive contact activities (Gehl, 1987), such as watching and listening, and the edge places were excellent locations for surveillance (Hall, 1992). When people are alone in a public space, the edges offer convenient and interesting locations for observing.

\section{Patterns of use by defined relationship groups}

In the analysis, three types of relationship were categorized using the distance between individuals (intimate, personal, and social) and named 'Intimate Pair', 'Intimate Group' and 'Social Group'. In the four study sites, the three groups accounted for $29 \%, 30 \%$, and $41 \%$ of the total, respectively. The data revealed that intimate distances only occurred for Intimate Pairs. The distances between individuals increased as group size increased. That finding supports Hall's (1992, p. 117) theory that describes intimate distance as 'lovemaking, wrestling, comforting, or protecting', which are unlikely to occur among more than two people.

The differences in patterns of use among the three relationship types were determined by examining the personal data collected during the observations. The majority of the 
Intimate Pairs were identified as lovers because about $69 \%$ of them comprised a man and a woman. The majority of the Intimate Groups included three or more people and the ages varied, which identified them as family-like or families. About $77 \%$ of the Social Groups comprised two people who maintained social distance from each other, and it was concluded that they might have been friends. Table 6 summarizes the three types of groups.

\begin{tabular}{lll}
\hline $\begin{array}{l}\text { Relationship } \\
\text { intensity distance }\end{array}$ & \multicolumn{1}{c}{ Group size } & \multicolumn{1}{c}{ Assumed relationship } \\
\hline Intimate & Two individuals & $\begin{array}{l}\text { Intimate Pair (e.g., partners, friends or } \\
\text { family members) }\end{array}$ \\
Personal & Three or more individuals & $\begin{array}{l}\text { Intimate Group (e.g., family members or } \\
\text { friends) }\end{array}$ \\
Social & Two or more individuals & $\begin{array}{l}\text { Social Group (e.g., acquaintances, } \\
\text { neighbours or colleagues) }\end{array}$ \\
\hline
\end{tabular}

Table 6 . Three types of relationship based on relationship intensity measured by physical distances between individuals

The analysis found that the three relationship types engaged in different activities and spatial occupancies. Table 4 above lists the five cluster types with their characteristics: relaxing, talking/sitting, playing, using a mobile phone, and standing. Table 7 illustrates the similarities and differences among the three types by comparing their activities using the five activity clusters. The Intimate Pairs mostly were using mobile phones (43.1\%), the Intimate Groups were mostly talking/sitting (32.5\%), and the Social Groups were mostly relaxing (48.2\%) and playing (43.0\%). The three types of groups were generally the same regarding standing. It was unexpected that the closest group, 'intimate pairs', mostly joined in the activity of 'using a mobile phone', as this activity seems to have no interaction involved. It should be noted that the pairs always used one phone together, to watch short videos or read the news together, for example. They would be close enough so that they could read from the small screen together. Most people now own their own phone, and they store private information on their phone, and in most cases people do not use their phones with other people. On this basis, using a mobile phone with another person may indicate that they have 
an intensely close relationship. It could also indicate that mobile phones are used more as entertainment devices than just for voice communication. Subsequently, activities in public spaces continuously change with the development of technology.

\begin{tabular}{llllll}
\hline & Relaxing & $\begin{array}{l}\text { Talking } \\
\text { Sitting }\end{array}$ & Playing & $\begin{array}{l}\text { Using a } \\
\text { mobile }\end{array}$ & Standing \\
& & & & phone & \\
& & & & 43.1 & 32.0 \\
\hline Intimate pair(\%) & 26.4 & 27.7 & 28.5 & 27.5 & 30.0 \\
Intimate group(\%) & 26.4 & 32.5 & 28.5 & 29.4 & 38.0 \\
Social group(\%) & 48.2 & 39.8 & 43.0 & 100.0 & 100.0 \\
Total(\%) & 100.0 & 100.0 & 100.0 & & \\
\hline
\end{tabular}

Table 7. Activities of the three relationship groups (the most frequent activity of each relationship group is marked in grey.)

Regarding the spatial occupancy of the three types of relationship, occupancy patterns differed according to the three regions on the maps. Figure 2 illustrates that information as lines. Intimate Pairs and Social Groups seemed similar because they tended to occupy the middle and edge regions more than the central regions, which was particularly obvious regarding Social Groups. This trend is also illustrated on the distribution map (Table 8), and the blue and yellow dots represent the intimate pairs and social groups. They rarely show up in the inner circles but are spread evenly in the middle and outer circles, especially for the yellow dots. On the other hand, Intimate Groups were most likely to occupy the central regions, followed by the middle regions, and they were least likely to occupy the edge regions. 


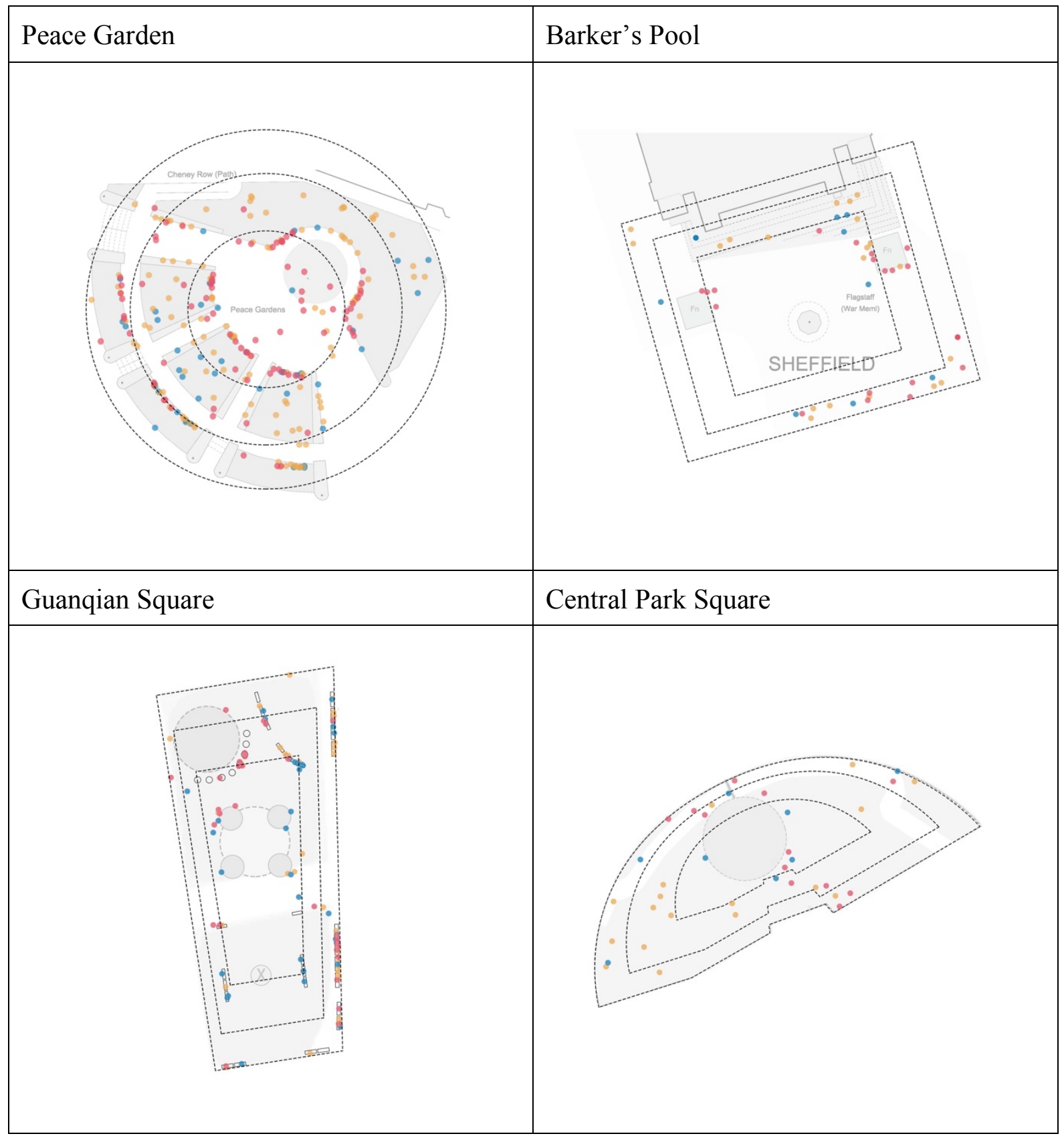

Table 8. Distribution of the three relationship types in four sites

Legend: Red = Intimate Group, Blue = Intimate Pairs, Yellow= Social Group 


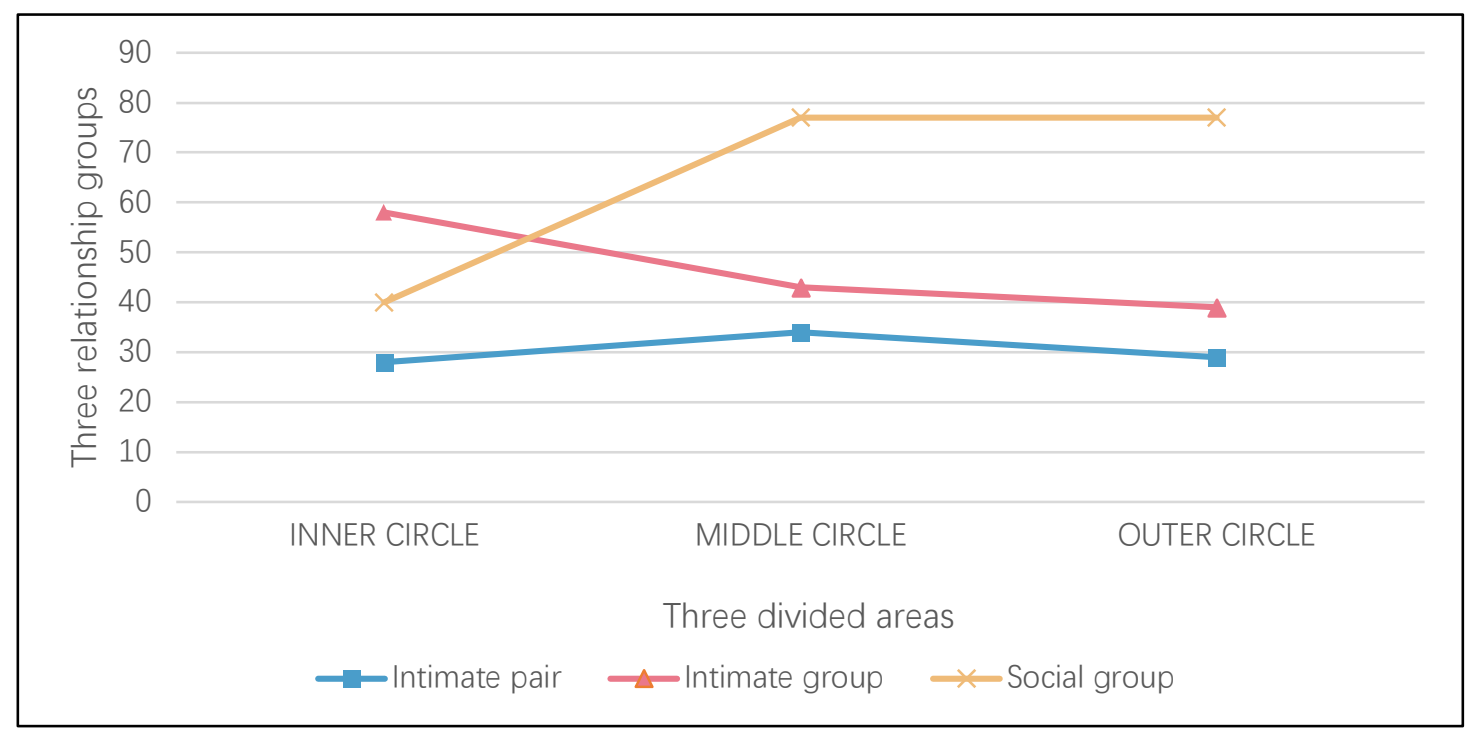

Figure 2. Spatial occupancy of the three relationship group types based on the mapped spatial regions (the colour of the lines are the same as the dots in Table 8)

To further illustrate spatial occupancy, the relationship types were investigated relative to the features of the public squares. The frequencies of the users' closeness to certain features were ascertained (Figure 3), which provides a clear understanding of the different spatial occupancies of the relationship types. Intimate Pairs were more likely than the other two types to be near trees, followed by Social Groups. Intimate Groups were more likely than the other two types to be near benches and a fountain, which were comfortable and playful areas. The Social Groups were more likely than the other groups to occupy lawns and steps, which are casual and open areas.

Spatial occupancies of the three relationship groups correspond with the results of the three circles' distribution as illustrated in the line graph (Figure 3). Trees, steps, and lawn, which were mostly occupied by intimate pairs and social groups, are all situated in the middle and edge of the public square. In contrast, intimate groups were not recorded near steps or trees and were rarely recorded on the lawn, which confirms the findings of the low frequency of the intimate groups occupying the middle and edge of different places. More of the intimate groups remained around the fountain. The fountains were located in the centres of thewhich confirms the findings of the high likelihood of intimate groups occupying the central regions of the public spaces. 
Spatial occupancies are related to the groups' activities and their social relationship. Intimate groups' high occupancies of the benches support their favourite activity — sitting and talking. Steps and lawns are suitable for relaxing casually, which explains why the social group mostly remained in these two places, and their high frequency of relaxing. Steps and lawns provide a free range of spaces for sitting and standing, and people have the flexibility of adjusting their distances to other people in those areas. This may be the reason why social groups are willing to remain there. In particular, when they are made up of more than two people, and they do not want to be too close to each other, they need areas like these. However, these three areas are all not proper sitting places as they can be dirty or wet some of the time. This may explain why intimate groups mostly used benches and had low frequencies of using steps and lawns. Because many intimate groups are made up of older people and children, who are more sensitive to which facilities they use in consideration of their health and safety (Holland et al., 2007). And for intimate pairs, trees may offer more privacy and can be quieter.

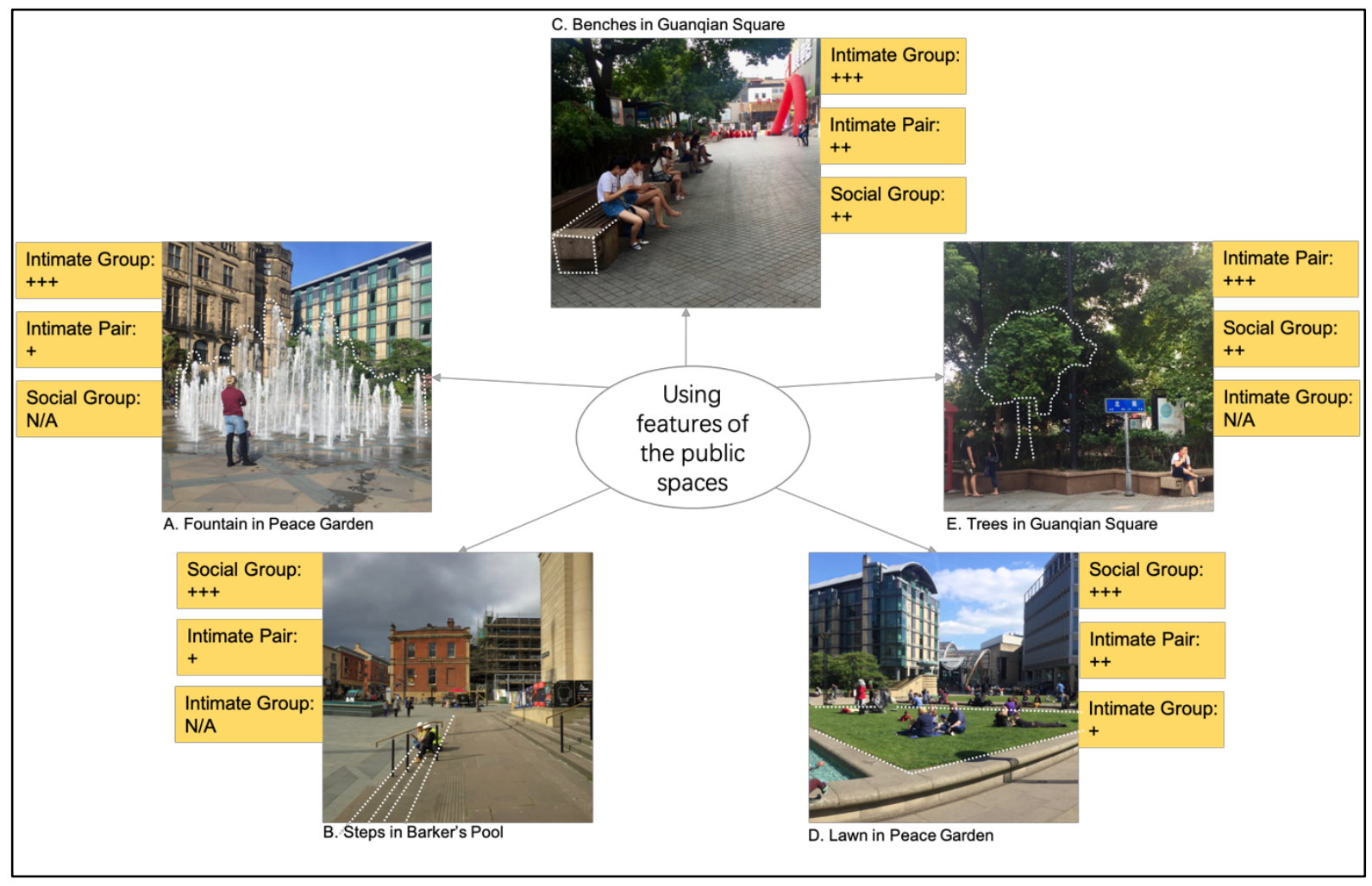

Figure 3. Likelihood of using features of the public spaces by relationship groups

Legend: $+=$ low frequency, $++=$ moderate frequency, $+++=$ high frequency 
Sources: A: Photographed by the author on 13.05.2017, B: Photographed by the author on 11.04.2017, C: Photographed by the author on 03.08.2017, D: Photographed by the author on 23.04.2017, E: Photographed by the author on 03.08.2017

\section{Discussion and conclusions}

The analysis found that there were no site differences with respect to the users' personal characteristics when the data were adjusted by omitting the large, unusual dance group from the data on one site. This dance group was a cultural factor at Central Park Square reflecting a common activity in China that influenced the age and group size distributions and negatively influenced the normal use at that study site. Cultural factors also influenced timing and activity types, with Suzhou users at the public spaces more likely to use the spaces at night than during daytime and Sheffield users more likely to use the spaces on sunny rather than less pleasant days.

The comparison of single to accompanied users found that the single users engaged in different types of activities and had different patterns of spatial occupancy than the group users. Women were more likely than men to be in groups than alone, indicating a gender difference in the public spaces. Compared to single users, group users tended to participate in multiple activities simultaneously, and their activities involved more interactions with other people. In terms of spatial occupancy, the single users confirmed the edge effect, but the group users were generally evenly distributed throughout the spaces.

Three types of group users were identified (Intimate Pair, Intimate Group and Social Group), and their patterns of use appeared to be different. Intimate Pairs were most likely to be using a mobile phone, Intimate Groups were most likely to be talking/sitting, and Social Groups were mostly playing and relaxing. Regarding these groups' spatial occupancies: (1) Intimate Pairs were more in the middles and edges than the central regions and they were more likely than the other types to use the areas under trees; (2) Intimate Groups were evenly distributed from the outer to the central regions and were more likely than the other types to use benches and fountains; and (3) Social Groups were highly unlikely to be in the central regions and they were more likely than the other types to use lawns and steps. 
To further consider the reasons for the different patterns of use found among the relationship types, group size, and age (which varied among the types) might have influenced their spatial occupancies and activities. For example, large groups need relatively more room, and children and elders are relatively sensitive to temperature and sunlight. In addition, relationship intensity might motivate people's behaviours, such as Intimate Pairs' desires for privacy. Further, certain activities relate to relationship intensity because activity type relates to distance. For example, Intimate Pairs' uses of mobile phones created situations where heads, thighs, and other body parts physically touched. The distances between people in Intimate Groups were close enough for an individual to hold or grasp the other person, which correlates with their most frequent activity (close conversations). Social distance is the "limit of domination' where no one touches or is touched by others. The Social Groups in this study preferred playing games, such as ball or card games, and relaxing, such as picnicking, reading, or drawing, which demonstrates this point because none of these activities involves physical touching.

Regarding the 'dancing group' in Central Park square, it is suggested to pay special attention when analysing Chinese public spaces. The large groups and massive noise they bring give negative effect not only on the other users but also on the surrounding residents. Although the modify method was starting to apply, which use earphone to deliver music to each dancer. The problem of occupying the spaces is still not solved. Chinese square dancing is a unique cultural phenomenon as its history demonstrates. Square dancing is believed to be a continuation of the 'Yangko dance', which is a form of traditional folk dance. Older people, especially those who grew up in Chinese villages, are more familiar with this kind of entertainment. When they were in their villages, they were not restricted by the performance location (Thepaper.cn, 2019), and contradictions gradually manifested during the course of urbanization. The function of public spaces is based on the awareness of and respect for other people's use of public spaces. The freedom to carry out the activities that one desires is a 'responsible freedom' with the recognition that a public space is a shared space (Varna \& Tiesdell, 2010; Carr, 1992). The desire for performing square dancing cannot be met in urban public spaces as it disturbs other users because the activity occupies a large area and generates a lot of noise. However, public spaces should be designed as 'containers' for 
human activities (Jacobs, 1961), and square dancers still have the rights to use the spaces. Perhaps there is an insufficient amount of tolerance for the plurality of values that leads to the contradictions between dancers and other users. Design has the responsibility of satisfying both the modern and the traditional in order to keep different people who live in the same space happy.

This study provides a new understanding of the patterns of use in public spaces based on types of relationship, which contributes to city planners' abilities to design sociability into public spaces. The three types of relationship were theoretically based on Hall's (1992) distance theory, which were then related to the users' activities. The findings point to the limitation of the edge effect, which was found for the single, but not the accompanied, users. Thus, planners should design public spaces with these differences in mind. This study has some limitations. First, because of limited time and human resources, the observations covered just one season. Because activities might vary throughout the year, further research over longer periods is suggested. Second, the spatial occupancies of users only focused on the edge effect, which was limited. Frequencies were used to assess similarities and differences, which was inefficient for illustrating users' distributions within the public spaces, and GIS mapping of exact locations would provide precise results.

This research did not receive any specific grant from funding agencies in the public, commercial, or not-for-profit sectors.

\section{Acknowledgements}

This work is supported by the joint program between Chinese Academy of Sciences and University of Sheffield. 


\section{References}

Balducci, A., \& Checchi, D. (2009). Happiness and quality of city life: The case of Milan, the richest Italian city. Int. Plan. Stud., 14 (1), 25-64.

BBC News China. (2013, 12.12). Dancing grannies raise a ruckus. http://www.bbc.co.uk/news/blogs-china-blog-25330651/ Accessed: 12 December 2013.

Bechtel, R. B., Marans, R., \& Michelson, W. (1987). Methods in environmental and behavioural research. New York: Van Nostrand Reinhold.

Carr, S. (1992). Public space. Cambridge: Cambridge University Press.

Cooper, M. C., \& Francis, C. (Eds.) (1998). People places: Design guidelines for urban open space. Toronto, Canada: John Wiley \& Sons.

De Jonge, D. (1967-1968). Applied hodology. Landscape, 17(2), 10-11.

Francis, M. (1984). Mapping downtown activity. Journal of Architecture and Planning Research, New York and Amsterdam: Elsevier Science Publishing,1,1:21-35.

Gehl, J. (1987). Life between buildings. Washington, DC: Island Press.

Gehl, J., \& Svarre, B. (2013). How to study public life. Washington, DC: Island Press.

Goličnik, B., \& Thompson, W. C. (2010). Emerging relationships between design and use of urban park spaces. Landscape and Urban Plan, 94(1), 38-53.

Goličnik Marusic. B., \& Marusic, D. (2012). Behavioural maps and GIS in place evaluation and Design. In B. M. Alam (Ed.), Application of Geographic Inf. Systems. Croatia: InTech.

Hall, E. (1992). The hidden dimension. Gloucester, MA: Peter Smith Pub.

Holland, C., Clark, A., Katz, J., \& Peace, S. (2007). Social interactions in urban public places. Bristol, UK: Policy Press.

Ittelson, W. H. (1970). The use of behavioural maps in environmental psychology. In H. M. Prohansky, W. H. Ittelson, \& L. G. Rivlin (Eds.), Environmental psychology: Man and his physical setting (pp. 658-668). New York: Rinehart \& Winston.

Jacobs, J. (1961). The death and life of great American cities. New York: Vintage Books.

Lipovská, B., \& Štěpánková, R. (2013). Assessing observation methods for landscape planning practice in rural villages. Current Urban Stud, 1(4), 102-109. 
Marcus, C., \& Francis, C. (1998). People places: Design guidelines for urban open space. New York: John Wiley.

Meng, Q., \& Kang, J. (2016). Effect of sound-related activities on human behaviours and acoustic comfort in urban open spaces. Science of The Total Environment, 573, pp. 481493.

Mowl, G., \& Towner, J. (1995). Women, gender, leisure, and place: Towards a more 'humanistic' geography of women's leisure. Leisure Stud, 14(2), 102-116.

Project for Public Spaces. (1981) What Do People Do Downtown?: How To Look at Mainstreet Activity. Washington, DC: National Trust for Historic Preservation.

Project for Public Spaces. (2017). What makes a successful place? Project for Public Spaces.

Retrieved from: https://www.pps.org/reference/grplacefeat/.

Staats, H., \& Hartig, T. (2004). Alone or with a friend: A social context for psychological restoration and environmental preferences. Journal of Environmental Psychology, 24(2), 199-211.

Stevens, Q. (2007). The ludic city: Exploring the potential of public spaces. London: Routledge.

Thepaper.cn. (2016). Square dance: the return of collectivism from 20 century. https://www.thepaper.cn/newsDetail_forward_1539463/ Accessed: 20 Oct. 2016.

Thwaites, K. and Simkins, I. (2005) Experiential landscape place: Exploring experiential potential in neighbourhood settings. Urban Design International, 10(1), pp. 11-22

Valentine, G. (1990). Women's fear and the design of public space. Built Environment, 16(4), $288-303$.

Varna, G., \& Tiesdell, S. (2010). Assessing the Publicness of Public Space: The Star Model of Publicness, Journal of Urban Des., 15:4, 575-598.

Walker, S. (2015). Illusory objects and fairground architecture. The Journal of Architecture, 20(2), 309-354.

Whyte, W. (1980). The social life of small urban spaces. New York: Project for Public Spaces.

Xiao, J., Tait, M, \& Kang, J. (2018). A perceptual model of smellscape pleasantness. Cities, 76, 105-115. 
Yang, W., \& Kang, J. (2005). Acoustic comfort evaluation in urban open public spaces. Applied Acoustics, 66(2), 211-229.

Yu, L., \& Kang, J. (2008). Effects of social, demographical, and behavioral factors on the sound level evaluation in urban open spaces. The Journal of the Acoustical Society of Am., 123(2), 772-783.

Zeisel, J. (1984). Inquiry by design: Tools for environment-behaviour research (Environment and behaviour series). Cambridge: Cambridge University Press.

Zhou, L. (2014). Music Is Not Our Enemy, But Noise Should Be Regulated: Thoughts on Shooting/Conflicts Related to Dama Square Dance in China. Research Quarterly for Exercise and Sport, 85(3), pp. 279-281. 